\title{
Effectiveness of a Planned Teaching Programme on Knowledge Regarding Common Hazards of Substance Abuse among the Higher Secondary School Students in a Selected School of Kashmir - An Evaluative Study
}

\author{
Najama Bibi ${ }^{1}$, Rais Ahmad Bhat ${ }^{2}$, Aisha Akther ${ }^{3}$ \\ ${ }^{1}$ M.Sc Child Health Nursing (MMINSR, SKIMS, Soura Srinagar J\&K ) \\ ${ }^{2}$ MBBS, MD Pediatrics, Senior Resident Deptt. of Pediatrics,SKIMS, Soura Srinagar J\&K \\ ${ }^{3}$ Research Supervisor, Deptt. Of Child Health Nursing MMINSR, SKIMS, Soura Srinagar J\&K
}

\begin{abstract}
Introduction: Substance abuse is a world -wide problem, is wide spread among adolescents and represents a serious public health problem. Aims \& Objectives: To assess the level of knowledge regarding common hazards of substance abuse among the higher secondary school students of Kashmir. To evaluate the effectiveness of planned teaching programme on the knowledge regarding common hazards of substance abuse among the higher secondary school students of Kashmir. To associate the pre-test knowledge of students with selected demographic variables. Hypothesis: $H_{1:}$ The mean post-test knowledge scores of the higher secondary school students regarding the hazards of substance abuse will be significantly higher than their mean pre-test knowledge scores at $0.05 \%$ level of significance. $\mathrm{H}_{2}:$ There is significant association between pre-test knowledge score and selected demographic variables. Material and Methods: 60 higher secondary students were chosen by simple random sampling to participate in the study, a structured questionnaire was introduced through pre-experimental one group pre-test post-test design for assessment of effectiveness of planned teaching programme. Results: There was significant increase in the mean post test knowledge of subjects after the administration of planned teaching programme as the mean post test knowledge score (36.11) was found to be significantly higher than the mean pre-test knowledge score (15.88) at 0.05 level of significance $(p<0.001)$. Conclusion: Planned teaching programme was an effective method for providing moderate to adequate knowledge and will help the higher secondary school students to prevent themselves from engaging into the evil of substance abuse, and to enable them to live better quality of life.
\end{abstract}

Keywords: Substance, hazards, knowledge, effectiveness, higher secondary students

\section{Introduction}

Psychoactive substance use poses a significant threat to the health, social and economic fabric of families, communities and nations. The extent of worldwide psychoactive substance use is estimated at 2 billion alcohol users, 1.3 billion smokers and 185 million drug users. In an initial estimate of factors responsible for the global burden of disease, tobacco, alcohol and illicit drugs contributed together $12.4 \%$ of all deaths worldwide in the year 2000. Looking at the percentage of total years of life lost due to these substances, it has been estimated that they account for $8.9 \% .^{(1)}$

College students are the most vulnerable group and are at high risk of drug abuse related problems compared to other population. The prevalence rate of drug abuse is highest among young adolescents and young adults, a large majority of whom are students Substance abuse by students in secondary schools and colleges is a serious problem. As it is gaining gradual popularity among college students, it would be vital to examine their knowledge towards substance abuse Health education is an important strategy of all the programmes to prevent and control drug abuse. $^{(2)}$

Children affected by substance abuse are considered as children in need of care and protection under the Juvenile
Justice Act, 2000 . Present evaluative study was conducted among higher secondary school students in a selected school of Tral , J\&K.

\section{Materials and Methods}

The conceptual framework based on the Ludwig Von Bertalanffy's General System Model was designed and implemented

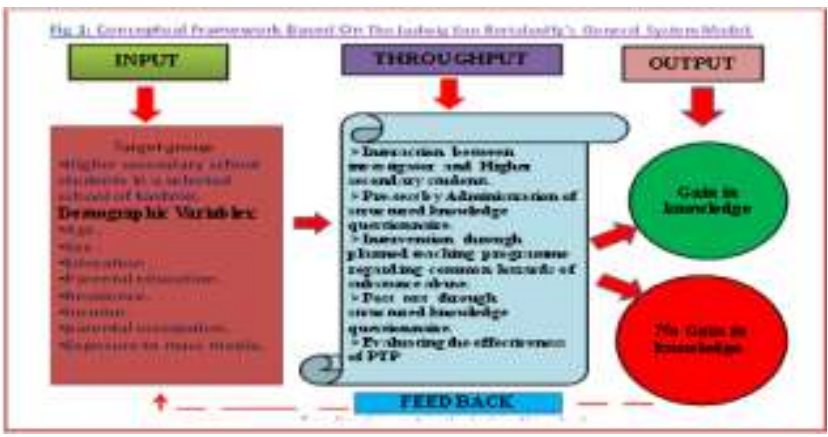

An evaluative study was done based on pre-experimental one group pre-test post-test design in December 2013, with study population of 60(sixty) higher secondary students studying in Government Higher Secondary School Tral, Pulwama Kashmir. Participants were chosen by probability simple random sampling technique. Pilot study was conducted in November 2013 on 10\% of study

Volume 6 Issue 12, December 2017 


\section{International Journal of Science and Research (IJSR) \\ ISSN (Online): 2319-7064}

Index Copernicus Value (2016): 79.57 | Impact Factor (2015): 6.391

population, \& they were not included in final study. Data of pre-test was obtained and planned teaching programme was administered to the students on the same day. Post-test was taken seven days after administration of planned teaching programme.

Study tool: A self structured knowledge questionnaire was used for collecting data, consisting of two sections- one section consisting of 8 items related to demographic characters and another based on knowledge about common hazards of substance abuse. There were totally 48 items \& each item had 4 choices. There was one correct response that carried 0ne (1) mark. The total score was 48 .

The knowledge scores obtained were graded as follows:

\begin{tabular}{|l|l|l|}
\hline Range & Scoring & Percentage \\
\hline $0-24$ & Poor & $0-50 \%$ \\
\hline $24-36$ & Average & $50 \%-75 \%$ \\
\hline $36-48$ & Good & $75 \%-100 \%$ \\
\hline
\end{tabular}

Ethical consideration: The ethical clearance was obtained from The Research Ethical Committee, Skims Deemed University, Srinagar and an informed consent was taken from the participants.

\section{Results}

The data obtained was analysed and interpreted in terms of objectives and hypothesis using descriptive and inferential statistics. Descriptive statistics used were mean, median, standard deviation with graphical presentation of data. Inferential statistics used to test hypothesis at 0.05 level of significance were t-test and ANOVA.

Majority of the subjects $(68.3 \%)$ were in the age group of 16- $18 \mathrm{yrs}, 25 \%$ were in the age group of $18-20 \mathrm{yrs}, 6.7 \%$ were in the age group $<16 \mathrm{yrs}$, , None $(0 \%)$ was above age group of $20 \mathrm{yrs}$. $50 \%$ of the subjects were males and $50 \%$ were females. $50 \%$ were studying in $11^{\text {th }}$ standard and $50 \%$ were studying in $12^{\text {th }}$ standard .Majority of the subjects(80\%) were rural dwellers, $20 \%$ were urban dwellers .Majority $(73.3 \%)$ of fathers of students were literate, while as $23.3 \%$ of mothers of the students were literate. Majority $(41.7 \%)$ of students had parental income of $<5000 \mathrm{Rs} /$ month, $15 \%$ of students had parental income of 5,000-10,000 Rs/month, $21.7 \%$ of students had parental income of $10,000-15,000 \mathrm{Rs} / \mathrm{month} .21 .7 \%$ of students had parental income of $>1,5000 \mathrm{Rs} /$ month. Majority of the mother's of subjects (95\%) were housewives, $5.0 \%$ of mothers of students were govt. employees, while as none was labourer or private employee. Among the fathers of students, $26.7 \%$ were labourers, $46.7 \%$ were Govt. employees, $13.3 \%$ were Private Employees and $13.3 \%$ were Businessman. Majority $(41.7 \%)$ of students had exposure to Radio \& TV, $26.7 \%$ were having exposure to print media, $11.7 \%$ were having exposure to internet, $20 \%$ of students had exposure to all these mass medias.

In the pre-test majority of the students (98.3\%) had fair knowledge, $1.7 \%$ had average knowledge and none had good knowledge; while as in post-test majority $(51.7 \%)$ of the students had average knowledge, $46.7 \%$ had good knowledge and only $1.7 \%$ had fair knowledge (fig 1). There was significant increase in the mean post test knowledge of subjects after the administration of planned teaching programme as the mean post test knowledge score (36.11) was found to be significantly higher than mean pre-test knowledge score (15.88) at 0.05 level of significance $(\mathrm{p}<0.001)$.

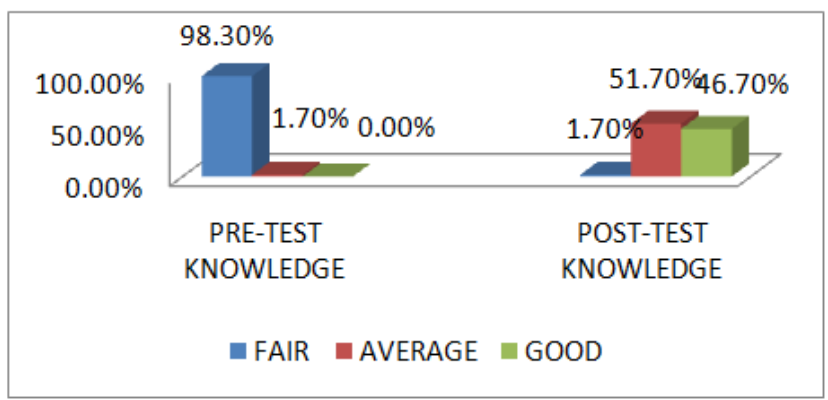

Figure 1: comparison of pre-test post-test knowledge

Table 1: Comparison Of Pre-Test And Post-Test Knowledge Level (Mean, Median And Standard Deviation)

\begin{tabular}{|c|c|c|c|c|c|c|}
\hline KNOWLEDGE & MEAN & S.D & MEDIAN & MIN & MAX & Range \\
\hline PRE-TEST & $\mathbf{1 5 . 8 8}$ & 4.00 & 16 & 5 & 25 & 20 \\
\hline POST-TEST & $\mathbf{3 6 . 1 1}$ & 4.73 & 35.5 & 21 & 45 & 24 \\
\hline
\end{tabular}

Table 2: knowledge gained and hypothesis testing

\begin{tabular}{|c|c|c|c|c|c|c|}
\hline \multirow{2}{*}{$\begin{array}{c}\text { KNOWLEDGE } \\
\text { SCORE }\end{array}$} & PRE-TEST & POST-TEST & $\begin{array}{c}\text { MEAN } \\
\text { DFFERENCE }\end{array}$ & S.D DIFFERENCE & t-VALUE & P-VALUE \\
\cline { 2 - 7 } & $15.88 \pm 4.0$ & $36.11 \pm 4.73$ & $\mathbf{2 0 . 2 3}$ & 5.87 & 26.66 & $<0.001$ \\
\hline
\end{tabular}

Volume 6 Issue 12, December 2017 www.ijsr.net 
International Journal of Science and Research (IJSR)

ISSN (Online): 2319-7064

Index Copernicus Value (2016): 79.57 | Impact Factor (2015): 6.391

Table 3: Association of demographic variables with pre-test knowledge

\begin{tabular}{|c|c|c|c|c|c|}
\hline S.NO & VARIA & & KNOWLEDGE(MEAN) & S.D & P-VALUE \\
\hline \multirow{3}{*}{1.} & \multirow{3}{*}{ AGE (YRS) } & $<16$ & 16.25 & 2.87 & \multirow{3}{*}{0.740} \\
\hline & & $16-18$ & 15.60 & 4.34 & \\
\hline & & $18-20$ & 16.53 & 3.31 & \\
\hline \multirow{2}{*}{2.} & \multirow{2}{*}{ SEX } & MALE & 15.00 & 4.13 & \multirow{2}{*}{0.735} \\
\hline & & FEMALE & 16.76 & 3.72 & \\
\hline \multirow{2}{*}{3.} & \multirow{2}{*}{$\begin{array}{l}\text { EDUCATIONAL } \\
\text { QUALIFICATION }\end{array}$} & $11^{\mathrm{TH}}$ & 16.50 & 3.65 & \multirow{2}{*}{0.456} \\
\hline & & $12^{\mathrm{TH}}$ & 15.26 & 4.29 & \\
\hline \multirow[b]{2}{*}{4.} & \multirow{2}{*}{ RESIDENCE } & RURAL & 15.50 & 3.81 & \multirow{2}{*}{0.277} \\
\hline & & URBAN & 17.41 & 4.52 & \\
\hline \multirow{4}{*}{5.} & \multirow{2}{*}{ EDUCATION OF MOTHER } & LITERATE & 15.50 & 4.73 & \multirow{2}{*}{0.455} \\
\hline & & ILLITERATE & 16.00 & 3.80 & \\
\hline & \multirow{2}{*}{ EDUCATION OF FATHER } & LITERATE & 16.25 & 4.22 & \multirow{2}{*}{0.373} \\
\hline & & ILLITERATE & 14.87 & 3.22 & \\
\hline \multirow{4}{*}{6.} & \multirow{4}{*}{ PARENTAL INCOME } & $<5000$ & 15.92 & 4.172 & \multirow{4}{*}{0.689} \\
\hline & & $5,000-10,000$ & 14.44 & 4.44 & \\
\hline & & $10,000-15,000$ & 16.38 & 3.73 & \\
\hline & & $>15,000$ & 16.30 & 3.83 & \\
\hline \multirow{6}{*}{7.} & \multirow{2}{*}{ MOTHER'S OCCUPATION } & GOVT. EMPLOYEE & 14.00 & 7.81 & \multirow{3}{*}{$0.036 *$} \\
\hline & & HOUSEWIFE & 15.98 & 3.80 & \\
\hline & \multirow{4}{*}{ FATHER'S OCCUPATION } & LABOURER & 15.81 & 4.32 & \\
\hline & & GOVT. EMPLOYEE & 16.00 & 4.13 & \multirow{3}{*}{0.854} \\
\hline & & PRIVATE EMPLOYEE & 14.87 & 3.18 & \\
\hline & & BUSINESSMAN & 16.62 & 4.10 & \\
\hline \multirow{4}{*}{8.} & \multirow{4}{*}{ EXPOSURE TO MASS MEDIA } & RADIO \& TV & 16.04 & 3.42 & \multirow{4}{*}{0.722} \\
\hline & & PRINT MEDIA & 15.93 & 3.94 & \\
\hline & & INTERNET & 14.28 & 2.98 & \\
\hline & & ALL & 16.41 & 5.68 & \\
\hline
\end{tabular}

There is statistically significant association between the pre-test knowledge and only one selected demographic variables i.e. mother's occupation $(\mathrm{p}<0.05)$. However there is no statistically significant association between pretest knowledge with demographic variables like age, gender, academic qualification, parental educational status, parental income and exposure to mass media $(\mathrm{p}>0.05)$.

\section{Discussion}

Drug or substance abuse is the self administration of a drug for non medical reasons in quantities which may impair an individual's ability to function effectively, \& which may result in social, physical or emotional harm ${ }^{(3)}$. Drug abuse is a worldwide problem, not confined to either the developed or the developing countries. It is not the problem of the individual but also affects the family and the society at large. In India substance abuse has been recognized as a growing problem in person from all works of life. It is wide spread among adolescents, young adults and others, drug abuse are most common during adolescence. At the age of 10-20 years, the use of drug abuses in adolescence represents a serious public health problems. $^{(4)}$

Substance abuse among adolescents has become a global challenge and also an important public health concern and for the past two decades there had been a dramatic increase in the demand for interventions to address the substance abuse problem.
This study has been conducted to evaluate the effectiveness of planned teaching programme on knowledge regarding common hazards of substance abuse among higher secondary school students in a selected school of kashmir.

Sreevani R. (2005) ${ }^{(5)}$ conducted a quasi experimental study in Tamka, Kolar District, among 30 adolescent students to assess the effectiveness of a planned teaching programme on the adverse effects of tobacco smoking using convenient sampling techniques.. A structured knowledge questionnaire was used to assess the knowledge prior to the PTP. Effectiveness of the PTP was assessed seven days after administering the same questionnaire. The findings revealed that there is significant difference between pretest and post-test knowledge of the students $(\mathrm{p}<0.001)$

In my study also there was a significant increase in the mean post test knowledge of subjects after the administration of planned teaching programme as the mean post-test knowledge score (36.11) is found to be significantly higher than the mean pre-test knowledge score $(\mathbf{1 5 . 8 8})$ at 0.05 level of significance $(p<0.001)$.

Franklin CA et al (1988) ${ }^{(6)}$ conducted a study to assess the awareness among college students to determine relationship of knowledge and selected variables in 100 pre-degree students (first year) from 3 colleges in Kolkata using a structured knowledge questionnaire. The results showed that the college students' knowledge of drug abuse was inadequate; no significant relationship was found between knowledge, sex and mass media exposure. But there was significant relationship between knowledge and parental education.

\section{Volume 6 Issue 12, December 2017}




\section{International Journal of Science and Research (IJSR) \\ ISSN (Online): 2319-7064}

Index Copernicus Value (2016): 79.57 | Impact Factor (2015): 6.391

In my study, it is found that there is statistically significant association between the pre-test knowledge with only one selected demographic variable i.e mother's occupation $(\mathrm{p}<$ 0.05). However there is statistically no significant association between pre-test knowledge with demographic variables like age, gender, academic qualification, parental educational status, parental income and exposure to mass media $(\mathrm{p}>0.05)$.

\section{Conclusion}

The study intended to assess the effectiveness of a Planned Teaching Programme on knowledge regarding common hazards of substance abuse among the higher secondary school students in a selected school of kashmir.

The following conclusion was drawn on the basis of the findings of the study:

Majority (98.3\%) of subjects were having poor level of knowledge before attending the planned teaching programme.

The mean post-test knowledge score of subjects is significantly higher than mean pre-test score. The mean pre-test knowledge score is 15.88 which increased to 36.11 in the post test, showing an average increase of $\mathbf{2 0 . 2 3}$, with $\mathrm{t}$-value 26.66 and $\mathrm{p}$-value of $<0.001$. This shows that the planned teaching programme (PTP) was effective in increasing the knowledge of students regarding common hazards of substance abuse.

There is significant association between pre test knowledge with only one selected demographic variable i.e., mothers occupation. However there is no significant association between pre test knowledge with other selected variables.

\section{Implications}

The study has implications in nursing education, nursing practice, nursing research and nursing administration.

\section{Limitations}

The study was limited to 60 higher secondary students only and to those who willingly were interested to participate in the study. Sample studied was limited; hence generalization of the findings is limited. Practice of students was not assessed.

\section{Recommendations}

The study can be replicated on larger sample; thereby finding can be generalized for a large population.

A similar study can be done on College students, students of different streams (medical, non-medical, arts, commerce, professionals etc) to assess the knowledge of students regarding common hazards of substance abuse and to observe the effectiveness of Planned teaching programme.
A similar study can be undertaken using other teaching strategy like self instructional module, Audio video assisted teaching programme

A similar comparative study can be done among rural and urban areas.Similar kind of study can be under taken in different setting.

\section{References}

[1] WHO- web page. http://www.who.int/substanceabuse/facts/global-burden/en/index. October 13, 2010)

[2] The I.C.D-10. Classification of mental and Behavioural disorders. Geneva: WHO publication; 2002

[3] Park K. Text book of Preventive and Social Medicine: $21^{\text {st }}$ edition. Jabalpur (India): M/s Banarsidas Bhanot Publishers; 2007. p. 772-773.

[4] Mandira Moddie. International conference report. Dealing with Drug abuse. 2002 March; p.400-405

[5] Sreevani R. Effectiveness of a planned teaching programme regarding adverse effects of tobacco smoking on knowledge gain on $\mathrm{X}^{\text {th }}$ standard students in a selected school of Kolar District. International conference. ISPN Feb. 2005; 46.)

[6] Franklin CA. Modis Medical Jurisprudence and Toxicology. 21st edition Bombay: N. M. Tripathi (p) LTD; 1988.4(Section II) 